\title{
INCIDENCE OF DIABETES MELLITUS AT THE FEDERAL MEDICAL CENTRE KATSINA, KATSINA STATE, NIGERIA: A RETROSPECTIVE STUDY
}

\author{
Suleiman, M.*, Abdulkarim, B. and Ahmed, A.
}

Department of Biology, Umaru Musa Yar'adua University, P. M. B. 2218, Katsina, Nigeria.

*Correspondence author: mymohammed007@yahoo.com

\begin{abstract}
A six-year (2002 - 2007) retrospective study of hospital records (in-patients) was carried out to investigate the incidence of Diabetes Mellitus in Katsina. The records showed that a total of 754 cases were attended within the study period. The study showed yearly increase in the incidence of the disease with the highest incidence of 288 (38.20\%) in the year 2007 and the least 65 (8.62\%) in the year 2002. More males suffered from the disease 456 (60.48\%) than females 298 (39.52\%). The incidence was also found to be high 289 (38.33\%) in the age range 65 and above, while age range 25 - 34 was least affected 28 (3.71\%). Ways on how to live free of Diabetes Mellitus were also recommended.
\end{abstract}

Keywords: Age Range, Diabetes Mellitus, Incidence, Hospital

\section{INTRODUCTION}

Diabetes Mellitus is a condition in which there is excess amount of sugar in the blood because it is not adequately transported into body organs by a hormone called insulin (NDCPN, 2007). The prevalence of Diabetes Mellitus and other communicable diseases is on the rise in African communities due to ageing of the population and drastic lifestyle changes accompanying urbanization and westernization (Gwatkin et al., 1999). The World Health Organisation (WHO, 1999) stated that a $12.2 \%$ rise in the number of adults with Diabetes Mellitus is projected by 2005 , to reach 300 million adults worldwide. It is further estimated that this figure would double in the next 25 years (NDCPN, 2007).

The literature relating to the prevalence of Diabetes in Nigeria is scarce (Nwafor and Owhoji, 2001). So far Diabetes is a well known major public health problem worldwide, there is therefore the growing tendency that every effort should be directed towards actively looking for the prevalence of Diabetes Mellitus in the Nigerian population. Mbanya et al. (1996) also reported the emergence of Diabetes Mellitus as a major health problem in Africa including Nigeria.

Researches on the incidence of Diabetes Mellitus in some hospitals of Nigeria showed that Diabetes is considerable cause of morbidity and mortality in Port-Harcourt (Dagogo Jack, 1990, Wokoma, 1999). In Nigeria, results of the National Survey conducted in 1990 showed that $2.21 \%$ of the adult population is diabetic with over one million adults suffering from the condition (NDCPN, 2007).

Ebenezer et al. (2003) studied the prevalence of type 2 diabetes in adult Nigerians and found its rates as $7.7 \%$ and $5.7 \%$ for males and females respectively. In the University of Port-Harcourt Teaching Hospital (UPTH) Diabetes Mellitus accounted for approximately $14 \%$ of all cases seen in the medical clinics in 1994, and over $18 \%$ of all the medical outpatient consultations in the same year (UPTH, 1994).
A prevalence of $1.6 \%$ Diabetes Mellitus in sub-urban Northern Nigeria was reported by Bakari et al. (1999). Prevalence of Diabetes Mellitus among Nigerians in Port-Harcourt correlates with socioeconomic status was studied by Nwafor and Owhoji (2001). They found that, the prevalence was as high as $23.4 \%$ among the high socio-economic group and $16 \%$ among the low socio-economic group.

Although cases of Diabetes Mellitus have been on the increase, no studies of its incidence in Federal Medical Centre, Katsina have been published. This study, therefore, for the first time was aimed at finding the incidence of Diabetes Mellitus among patients attending the Federal Medical Centre, Katsina from $2002-2007$.

\section{MATERIALS AND METHODS}

The relevant hospital records of medical cases of Diabetes Mellitus seen systematically in Federal Medical Centre, Katsina from 2002 - 2007 were retrieved with the aim of investigating the incidence of the disease in Katsina. A total of 754 cases were analysed by statistical testing.

\section{RESULTS}

A total of 754 cases of Diabetes Mellitus were studied in this work. The incidence of occurrence of the disease was recorded to be as high as 288 cases $(38.20 \%)$ in the year 2007 , followed by 141 cases $(18.70 \%)$ in the year 2006,102 cases $(13.53 \%)$ in the year 2005, 86 cases (11.41\%) in 2004 and then 72 cases $(9.55 \%)$ in the year 2003 . The least occurrence was recorded in the year 2002 with 65 cases $(8.62 \%)$ (Table 1). More males 456 (60.48\%) suffered from the disease than females 298 (39.52\%) (Table 2). People of age range $65-74$ were the most affected, $289(38.33 \%)$, followed by $55-64,192(25.46 \%), 45$ - 54, $165(21.88 \%)$ and $35-4480(10.61 \%)$, while age range $25-34$ were least affected, 28 (3.71\%) (Table 3). 
Bajopas Volume 4 Number 2 December, 2011

Table 1: Frequency of occurrence of Diabetes Mellitus disease in six years (2002 - 2007) among patients attending Federal Medical Centre, Katsina.

\begin{tabular}{|c|c|c|c|c|c|c|c|c|c|c|c|c|c|c|c|c|c|c|c|c|c|c|c|c|c|}
\hline \multirow{2}{*}{$\frac{\text { Month }}{\text { Year }}$} & \multicolumn{2}{|c|}{ Jan. } & \multicolumn{2}{|c|}{ Feb. } & \multicolumn{2}{|c|}{ March } & \multicolumn{2}{|c|}{ April } & \multicolumn{2}{|c|}{ May } & \multicolumn{2}{|c|}{ June } & \multicolumn{2}{|c|}{ July } & \multicolumn{2}{|c|}{ Aug. } & \multicolumn{2}{|c|}{ Sept. } & \multicolumn{2}{|c|}{ Oct. } & \multicolumn{2}{|c|}{ Nov. } & \multicolumn{2}{|c|}{ Dec. } & \multirow[b]{2}{*}{$\begin{array}{l}\text { Total } \\
(\%)\end{array}$} \\
\hline & $\mathbf{M}$ & $\mathbf{F}$ & $\mathbf{M}$ & $\mathbf{F}$ & $\mathbf{M}$ & $\mathbf{F}$ & $\mathbf{M}$ & $\mathbf{F}$ & $\mathbf{M}$ & $\mathbf{F}$ & $M$ & $\mathbf{F}$ & $\mathbf{M}$ & $\mathbf{F}$ & $\mathbf{M}$ & $\mathbf{F}$ & $M$ & $\mathbf{F}$ & $\mathbf{M}$ & $\mathbf{F}$ & $\mathbf{M}$ & $\mathbf{F}$ & $\mathbf{M}$ & $\bar{F}$ & \\
\hline 2002 & 4 & 1 & 4 & 2 & 2 & 1 & 3 & 2 & 5 & 0 & 5 & 1 & 3 & 2 & 4 & 2 & 3 & 1 & 3 & 2 & 4 & 2 & 6 & 3 & $65(8.62)$ \\
\hline 2003 & 5 & 4 & 6 & 2 & 4 & 2 & 4 & 1 & 5 & 4 & 1 & 2 & 5 & 1 & 7 & 3 & 2 & 1 & 3 & 0 & 3 & 3 & 3 & 1 & $72(9.55)$ \\
\hline 2004 & 4 & 2 & 3 & 3 & 4 & 4 & 3 & 4 & 6 & 4 & 3 & 1 & 5 & 1 & 3 & 3 & 4 & 1 & 3 & 3 & 6 & 4 & 8 & 4 & $86(11.41)$ \\
\hline 2005 & 5 & 4 & 5 & 3 & 7 & 3 & 4 & 3 & 6 & 7 & 5 & 4 & 5 & 5 & 3 & 3 & 4 & 5 & 6 & 3 & 4 & 2 & 4 & 3 & $102(13.53)$ \\
\hline 2006 & 7 & 4 & 7 & 5 & 8 & 3 & 8 & 5 & 6 & 3 & 6 & 4 & 11 & 3 & 8 & 2 & 11 & 8 & 6 & 5 & 8 & 5 & 4 & 4 & $141(18.70)$ \\
\hline 2007 & 9 & 8 & 13 & 10 & 18 & 13 & 16 & 17 & 10 & 14 & 20 & 13 & 15 & 10 & 8 & 6 & 8 & 5 & 16 & 8 & 18 & 14 & 12 & 7 & $288(38.20)$ \\
\hline Total & & & & & & & & & & & & & & & & & & & 7 & & & & 75 & & 100 \\
\hline
\end{tabular}

Key: $\mathrm{M}=$ Male, $\mathrm{F}=$ Female

Table 2: Occurrence of Diabetes Mellitus disease by sex in Federal Medical Centre, Katsina

\begin{tabular}{cccccccc}
\hline Year & $\mathbf{2 0 0 2}$ & $\mathbf{2 0 0 3}$ & $\mathbf{2 0 0 4}$ & $\mathbf{2 0 0 5}$ & $\mathbf{2 0 0 6}$ & $\mathbf{2 0 0 7}$ \\
\hline Male & 46 & 48 & 52 & 57 & 90 & 163 \\
Female & 19 & 24 & 34 & 45 & 51 & 125 \\
\hline Total & $\mathbf{6 5}$ & $\mathbf{7 2}$ & $\mathbf{8 6}$ & $\mathbf{1 0 2}$ & $\mathbf{1 4 1}$ & $\mathbf{2 9 8}(39.52 \%)$ & $\mathbf{2 8 8}$ \\
\hline
\end{tabular}

Table 3: Occurrence of Diabetes Mellitus by age range in Federal Medical Centre, Katsina (2002 - 2007)

\begin{tabular}{|c|c|c|c|c|c|c|}
\hline Year & $25-34$ & $35-44$ & $45-54$ & $55-64$ & $65-74$ & Total (\%) \\
\hline 2002 & 4 & 9 & 14 & 17 & 21 & $65(8.62 \%)$ \\
\hline 2003 & 3 & 11 & 16 & 19 & 23 & $72(9.55 \%)$ \\
\hline 2004 & 4 & 7 & 15 & 26 & 34 & $86(11.41 \%)$ \\
\hline 2005 & 5 & 11 & 23 & 24 & 59 & $102(13.53 \%)$ \\
\hline 2006 & 6 & 15 & 26 & 38 & 56 & $141(18.70 \%)$ \\
\hline 2007 & 6 & 27 & 71 & 68 & 116 & $288(38.20 \%)$ \\
\hline Total & $28(3.71 \%)$ & $80(10.61 \%)$ & $165(21.88 \%)$ & 192(25.46\%) & $289(38.33 \%)$ & $754(100 \%)$ \\
\hline
\end{tabular}




\section{DISCUSSION}

This work shows that Diabetes Mellitus is more prevalent in 2007, while the least incidence was recorded in 2002. There was a steady increase in the occurrence of the disease from the year 2002 to the year 2007 and highest rate of increase in the prevalence might be attributed to change in lifestyle associated with feeding habits and urbanization. This agrees with the findings of Omran (1971), Mosley et al. (1993) and Mbanya et al. (2001).

Males appeared to be affected more than the females. This agrees with the findings of Nwafor and Owhoji (2001) and Ebenezer et al. (2003). This may be due to high fat consumption by males and corresponding reduced complex carbohydrate intake and sedentary lifestyle.

Older individuals were the most affected group, while the younger ones were least affected. This agrees with the findings of Ebenezer et. al. (2003), Bakari and Onyemelukwe (2004) and NDCPN (2007). Individuals of age $\geq 65$ were more affected due the fact that people of this area do not engage themselves in physical activities such as exercise at

\section{REFERENCES}

Bakari, A. G. and Onyemelukwe, G. C. (2004). Glucose intolerance among apparently healthy Hausa/Fulani Northern Nigerians. Annals of African Medicine, 3: 32 - 34.

Bakari, A. G., Onyemelukwe, G. C., Sani, B. G., Hassan, S. S. and Aliyu, T. M. (1999). Prevalence of diabetes mellitus in sub-urban Northern Nigeria: Results of Public Screening Survey. Diabetes International, 9: 59 - 60.

Dagogo-Jack, S. (1990). Experience from the organisation of a local diabetes associated in Port-Harcourt, Nigeria. Practical Diabetes and Digestion, 1(4): 145 - 147.

Ebenezer, A., Osaratin, O., Anele, E. I., Aoron, O. And Babatunde, S. (2003). Type 2 diabetes in adult Nigerians: A study of its prevalence and risk factors in Port-Harcourt, Nigeria. Diabetes Research and Clinical Practice, 62: $177-185$.

Gwatkin, D., Guillot, M. and Hevveline, P. (1999). The burden of diseases among the global poor. Lancet, 354: 586 - 589.

Mbanya, J. C., Bocinni, F. and Nagan, K. (1996). Guidelines for the management of NIDDIM in Africa. A consensus document. Greece, Novo, Nordisk. A/S Pp $1-35$.

Mbanya, J. C., Sobngwi, E., Mauvais - Jarvis, F., Vexiau, P. and Gautier, J. F. (2001). Diabetes in Africa: Epidemiology and clinical specificities. Diabetes metab. (Paris). 27: $628-634$. old age which leads to accumulation of fats and inadequate burning of sugar in their body. This might be attributed to the fact that at older ages physiological and metabolic activities tend to slow down and the immune system to fight infections is also weak.

\section{CONCLUSION}

This study has revealed the incidence of Diabetes mellitus in Federal Medical Centre, Katsina. There was an increase in occurrence of the disease during the period of study, and as such there is need for more diabetic awareness programme so as to identify people with diabetes early enough with the aim of providing treatment regimens.

\section{RECOMMENDATIONS}

People should engage themselves in physical activity or exercise regularly and be encouraged to live on diet that is high in fibre content. Also patients who suspect they may have Diabetes Mellitus should visit nearest hospital for early assessment and confirmation.

Mosley, W. H., Bobadilla, J. L. and Jamiso, D. T. (1993). The Health Transition: Implications for health policy in developing countries. New York Oxford University Press. P70.

NDCPN (2007). Diabetes Control and Prevention. Pamphlet,1 - 4. Non-communicable Disease Control Programme of Nigeria.

Nwafor, A. and Owhoji, A. (2001). Prevalence of Diabetes Mellitus among Nigerians in PortHarcourt correlates with socio-economic status. Journal of Applied Sciences and Environmental Management, 5(1): 75 - 77.

Omran, A. R. (1971). The epidemiologic transition: A theory of the epidemiology of population change. Millank Memorial Fund Quarterly, 60 $-65$.

UPTH (1994). Medical Records: Out Patient Services, pp 5 - 11. University of Port-Harcourt Teaching Hospital.

WHO (1999). Definition, Diagnosis and Classification of Diabetes mellitus and its complications. Part I. World Health Organization, Geneva, 1999.

Wokoma, F. S. (1999): Hypertension in non-insulin dependent diabetes Nigerians. A comparative of normotensive subgroups. Diabetes International, 3: 57 - 58. 